\section{Kidney \\ Blood Pressure Research}

\title{
A Missense Mutation of the $\alpha$-Galacto- sidase A Gene in a Chinese Family of Fabry Disease with Renal Failure
}

\author{
Chunli Wang $^{\mathrm{a}}$ Yang Wang $^{\mathrm{b}}$ Feng Zhuc ${ }^{\mathrm{c}}$ Jing Xiong ${ }^{\mathrm{a}}$
}

aDepartment of Nephrology, Union Hospital, Tongji Medical College, Huazhong University of Science \& Technology, Wuhan, China 430022; 'bepartment of Emergency, Union Hospital, Tongji Medical College, Huazhong University of Science \& Technology, Wuhan, China 430022; 'Department of Cardiology, Union Hospital, Tongji Medical College, Huazhong University of Science \& Technology, Wuhan, China 430022; Chunli Wang and Yang Wang contributed equally to this work

\section{Key Words}

Fabry disease $\cdot$ Missense mutation $\cdot$ Renal failure

\begin{abstract}
Background: Fabry disease (FD) is a rare disease due to an X-linked recessive inborn error of glycosphingolipid metabolism resulting from the mutations of the $\alpha$-galactosidase $A$ $(\alpha-g a l$ A) gene. FD is rare in Chinese and the data on clinic and genetic features of FD is still limited. Methods: In this study, the $\alpha$-gal A gene of a Chinese family diagnosed with FD was analyzed for mutations and the genetic features of FD in this family were presented. Results: The $\alpha$-gal A activity of the proband in this family was $0.03 \mathrm{nmol} / \mathrm{ml} / \mathrm{h}$ in the whole blood. By PCR amplification and sequencing of the $\alpha$-gal A gene exons, a single C-to- $T$ transition was identified in codon 112 of exon 2. This C-to-T transition, mapping to position 334 in the CDNA of the $\alpha$-gal $A$ gene, was a missense mutation predicting a substitution of arginine to cysteine (p.R112C), which disrupts the normal activity of $\alpha$-gal A enzyme. No further mutations were found in other exons of the $\alpha$-gal A gene. In contrast to previous reports, in this family, all of the five male patients developed end-stage renal failure due to this missense mutation. Conclusions: These findings suggest that the missense mutation, p.R112C, in $\alpha$-gal A gene ablates its activity and results in the development of FD with the renal damage.
\end{abstract}

Copyright $\odot 2013$ S. Karger AG, Basel

\section{Introduction}

Fabry or Anderson-Fabry disease (FD) is a rare X-linked recessive inborn error of glycosphingolipid metabolism. Disease prevalence has been estimated to be about 1:40,000 


\section{Kidney \\ Blood Pressure Research}

Kidney Blood Press Res 2013;37:221-228

\begin{tabular}{l|l}
\hline DOI: $10.1159 / 000350147$ & C 2013 S. Karger AG, Basel
\end{tabular}

Published onlıne: June 08, 2013

www.karger.com/kbr

male subjects. The mutations of the $\alpha$-galactosidase A ( $\alpha$-gal A) gene induces the deficient activity of the lysosomal hydrolase $\alpha$-gal A enzyme, which leads to impaired degradation and subsequent accumulation of globotriaosylceramide in multiple tissues and organs [1]. The progressive accumulation of globotriaosylceramide and globotriaosylceramide takes place within the endothelial and smooth muscle cells of the vascular system, myocardial cells, nervous system, and in all kind of cells of the kidney, eventually leading to organ dysfunction [2].

Typical and severe clinical manifestations of FD in hemizygotes include acroparesthesia, angiokeratoma, hypohidrosis, and corneal and lenticular opacities, generalized vascular disease affecting the kidneys, heart, brain, and the gastrointestinal tract. The renal function is disturbed in all hemizygous male and in some heterozygous female patients, and renal dysfunction with progression to end-stage renal failure is a common manifestation in males in their third to fifth decade of life. Usually, death occurs from cerebral and/or cardiovascular complications in patients undergoing chronic dialytic treatment [2-7]. In FD patients, the renal injury is universal: accumulation of glycosphingolipids occurs in endothelial cells of vessels and in the epithelial cells of the Henle's loop and distal tubule, inducing an early impairment in renal concentrating ability; the involvement of proximal tubule causes Fanconi syndrome; all kinds of glomerular cells are involved, especially podocytes, and glomerular proteinuria may occur at a young age [3]. According to the natural history of renal disease in Fabry patients described by Branton et al. [4], the mean rate at which glomerular filtration rate (GFR) decreases is $12.2 \pm 8.1 \mathrm{ml} / \mathrm{min} / 1.73 \mathrm{~m}^{2} /$ year (range 3.3 to $33.7 \mathrm{ml} / \mathrm{min} / 1.73 \mathrm{~m}^{2}$ / year).

FD is a rare but recognized disease in Chinese population. Although the prevalence of the FD in the Chinese population is unknown, the actual prevalence of FD could be underestimated due to the difficulty in recognizing and diagnosing this disease. Discrepancies in the clinical manifestations of FD (i.e., eye disorders and hypertension) exist between cases found in China and those detailed in Western reports [5]. In this study, we have investigated a Chinese family diagnosed with FD and presented here genetic features of FD in this family by performing mutational analysis of the $\alpha$-gal A gene.

\section{Subjects and Methods}

\section{Subjects}

A 26-year-old male presented with end-stage renal disease (ESRD) was treated at Union Hospital, Tongji Medical College, Huangzhong University of Science \& Technology, Wuhan, China for the regular hemodialysis. Along with ESRD, he had experienced fatigue, hypohidrosis, and painful acroparesthesias since he was 12 years old, which indicates that the primary disease of this patient might be FD. So the hereditary pedigree was further investigated, and plasma $\alpha$-gal A activity and $\alpha$-gal A gene analysis was examined.

Plasma $\alpha$-gal A activity assay

Plasma $\alpha$-gal A activity was determined using the substrate 4-methylumbelliferyl $\alpha$-D-galactopyranoside ( $5 \mathrm{mmol} / \mathrm{L}$ ) freshly prepared in $117 \mathrm{mmol} / \mathrm{L} \mathrm{N}$-acetyl-D-galactosamine/50 mmol/L citric-phosphate buffer, $\mathrm{pH} 4.6$, before every assay. In brief, $50 \mu \mathrm{l}$ of plasma was mixed with $300 \mu \mathrm{l}$ of the substrate solution, incubated at $37^{\circ} \mathrm{C}$ for 2 hours, and $0.2 \mathrm{~N}$ glycine- $\mathrm{NaOH}$ was added to stop the reaction. Fluorescence intensity was measured with the excitation and emission wavelengths of 365 and $450 \mathrm{~nm}$, respectively [6-7].

Molecular analysis of $\alpha$-gal A gene

For the study protocol, informed written consent was obtained from all patients. Genomic DNA was isolated from the whole blood of the proband and his sister by a routine method. The sequence of $\alpha$-gal Agene 


\section{Kidney Blood Pressure Research}

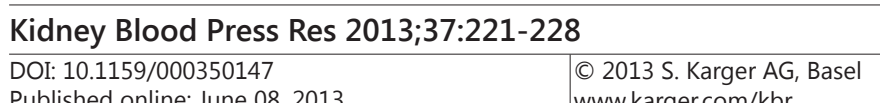

Published onIIne: June 08, 2013 www.karger.com/kbr

Wang/Wang/Zhu/Xiong: Gene Mutation of $\alpha$-gal A in a Chinese FD Family

was obtained from the European Bioinformatics Institute (EBI) of the European Molecular Biology Laboratory (EMBL) through its web site. The nucleotides were numbered by EMBL-EBI accession number X14448. Seven exons of the $\alpha$-gal A gene was amplified by polymerase chain reaction (PCR) with six sets of primers as shown in Table 1. The PCR mixture consisted of $0.3 \mu \mathrm{M}$ primers, $200 \mu \mathrm{M} \mathrm{dNTP}$, $1.25 \mathrm{U}$ of Taq DNA polymerase and $50 \mathrm{ng}$ of genomic DNA in a total $25 \mu \mathrm{l}$ volume. The thermal cycle profile was 30 cycles of denaturation at $94^{\circ} \mathrm{C}$ for 30 seconds, anneal at specific temperature indicated in Table 1 for 45 seconds and a final extension of 1 minute at $72^{\circ} \mathrm{C}$. DNA sequencing was processed in both directions and the mutation identification was also performed by an ABI-PRISM3730 automated sequencer (Sangon biotech company, Shanghai, China). Genomic DNA from normal people was used as control.

\section{Results}

Pedigree investigation

We found a rare FD family in China

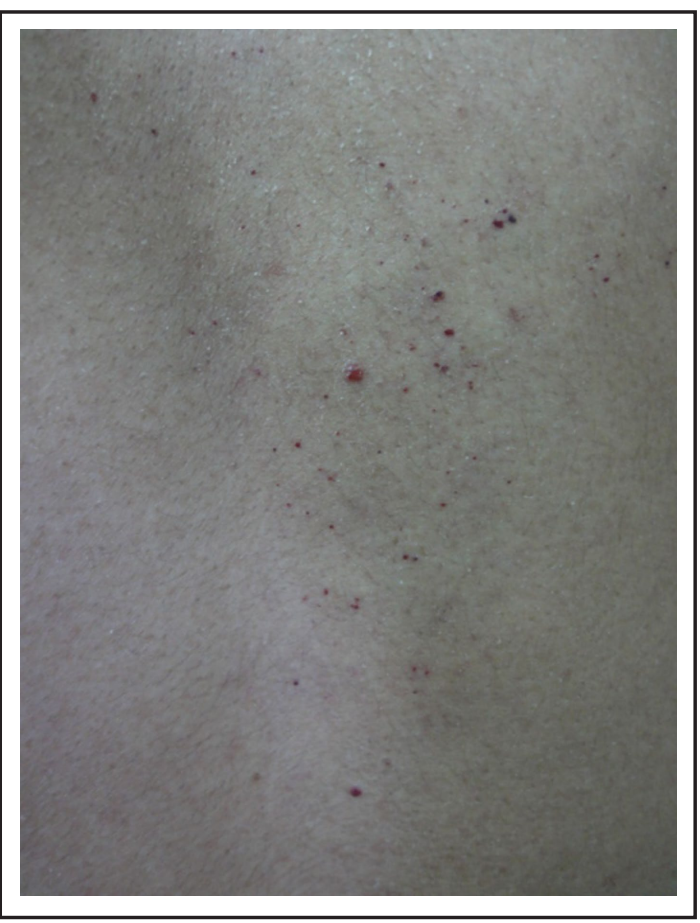

Fig. 1. Skin injury. Skin angiokeratomata was found on the back of the proband. according a patient with ESRD. The proband, a 26-year-old male, was presented with ESRD 3 years ago. He had experienced fatigue, hypohidrosis, and painful acroparesthesias since he was 12 years old, then he had been hospitalized due to kidney failure symptom at the age of 17. He developed ESRD six years later, and was treated at our hospital for the regular hemodialysis from then on. The further physical examination revealed no abnormal findings in his chest or abdomen. Moreover, ophthalmological or neurologic examination did not reveal any corneal lesion or cerebrovascular event, respectively. However, the patient was suffered by the unendurable recurrent pain in his hands and feet and countless small dark red to black papules were found on his back (Figure1). Urinalysis was failed due to anuria. As shown in Table 2, the patient was confirmed FD by demonstration of an extremely low plasma $\alpha$-gal A activity of $0.03 \mathrm{nmol} / \mathrm{ml} / \mathrm{h}$ (normal range $8.8-14.5 \mathrm{nmol} / \mathrm{ml} / \mathrm{h}$ ).

The further investigation revealed the positive family history, and the family pedigree was shown in Table 2 and Figure 2. The proband's grandfather, patient I1, died of ESRD. The proband's mother, patient II7, had suffered from strokes and paralysis down from her waist for eight years and died of a cerebrovascular accident (CVA) in her forties. Stroke has been considered as a frequent complication of FD caused by alterations in cerebral vessels [8]. Further investigation did not reveal any other typical clinical manifestations of FD, such as skin lesion, acroparaesthesia, corneal abnormality, kidney disease or cardiovascular problems. She had three sisters, among them the eldest one (II1) was healthy before she died in her seventies. However, her two youngest sons (III7 and III9) developed ESRD and had kidney transplantation. It seems that she was an asympotomatic heterozygous carrier. Another two sisters (II3 and II5) did not have any FD manifestation before they died, and all of their descendants were healthy to date.

The proband's elder sister, patient III15, was healthy in the past 30 years. No positive symptom of FD was found and her plasma $\alpha$-Gal A activity was in the normal range $(9.0 \mathrm{nmol} / \mathrm{ml} / \mathrm{h})$. The proband's younger brother, patient III18, developed ESRD at the age of 


\section{Kidney \\ Blood Pressure Research}

Table 1. $\alpha$-gal A gene primer records.
Kidney Blood Press Res 2013;37:221-228

\begin{tabular}{l|l}
\hline DOI: 10.1159/000350147 & (C) 2013 S. Karger AG, Basel
\end{tabular}

Published onIIne: June 08, 2013

www.karger.com/kbr

Table 2. Clinical characteristics of affected family members with FD.

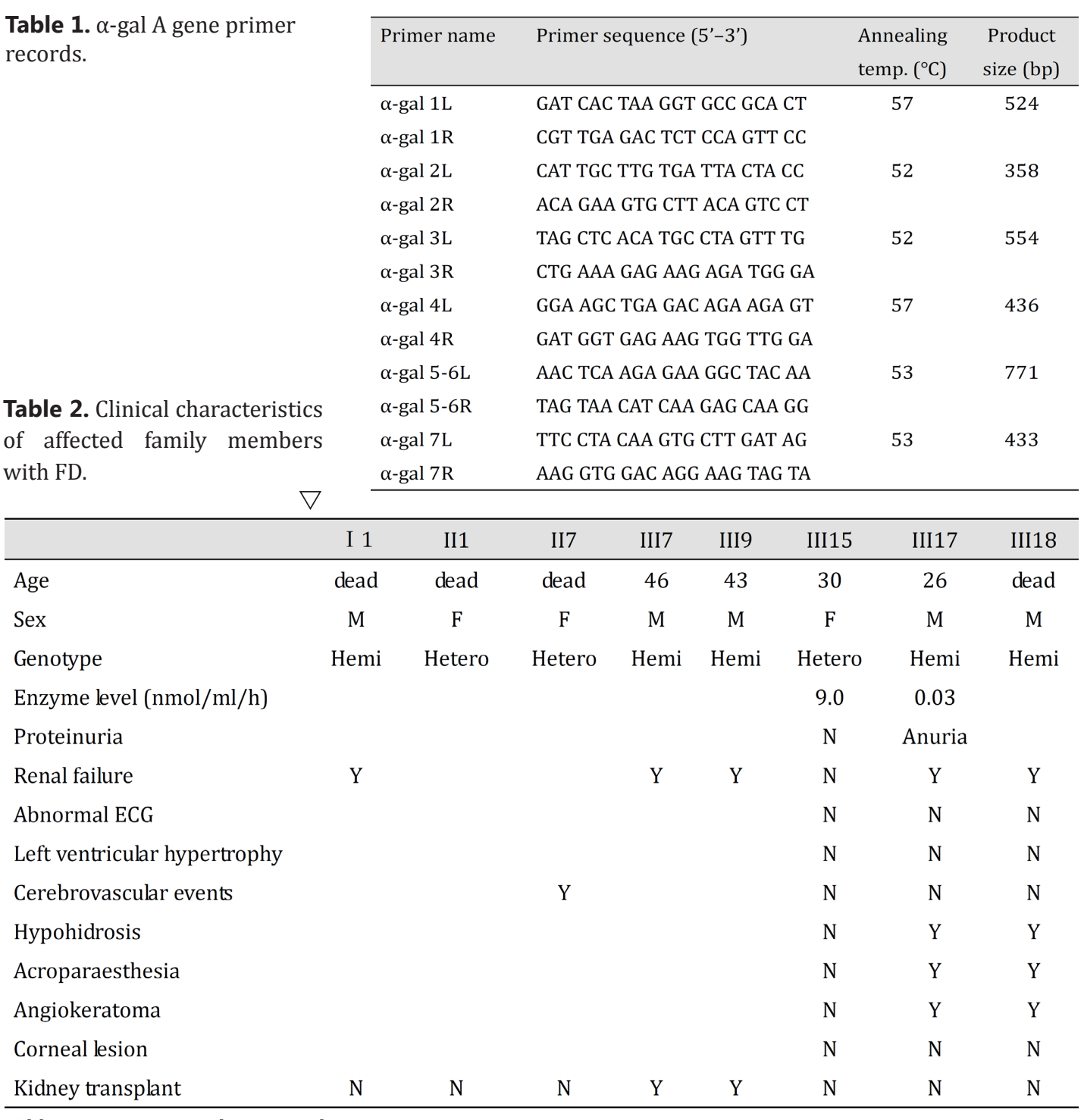

Abbreviations: M=Male, F=Female, Hemi= Hemizygote, Hetero= Heterozygote, $Y=Y e s, N=$ No.

10 as a result of unknown etiology and died six years later. His clinical manifestations were similar to those of the proband. However, the onset of the disease was earlier and much more severe.

\section{Genetic analysis}

The complete genomic and cDNA sequences of the human $\alpha$-gal $\mathrm{A}$ gene have been determined. The $14 \mathrm{~kb}$ genomic sequence of $\alpha$-gal A contains seven coding exons and 12 intronic Alu repetitive elements [9]. Seven exons of the $\alpha$-gal A gene was amplified by PCR and the result revealed a single C-to-T transition in codon 112 of exon 2 (Figure 3). This transition, mapping to position 334 in the cDNA of the $\alpha$-gal A gene, resulted in substitution of predicted arginine to cysteine (p.R112C), which may be responsible for the abnormal activity of $\alpha$-gal A enzyme in the blood of the proband investigated.

This result demonstrated that the proband (patient III17) was a hemizygote of p.R112C and his sister (III15) was a heterozygote of p.R112C since the bases T and C were both detectable in her DNA sequencing. No mutations were found in other six exons of their $\alpha$-gal A genes. 


\section{Kidney Blood Pressure Research}

Fig. 2. Family pedigree. Circles are females and squares are males. Filled symbols are affected patients. Half-filled symbols mean carriers without symptoms. Slash symbols are deceased members. The arrow indicates the proband patient.

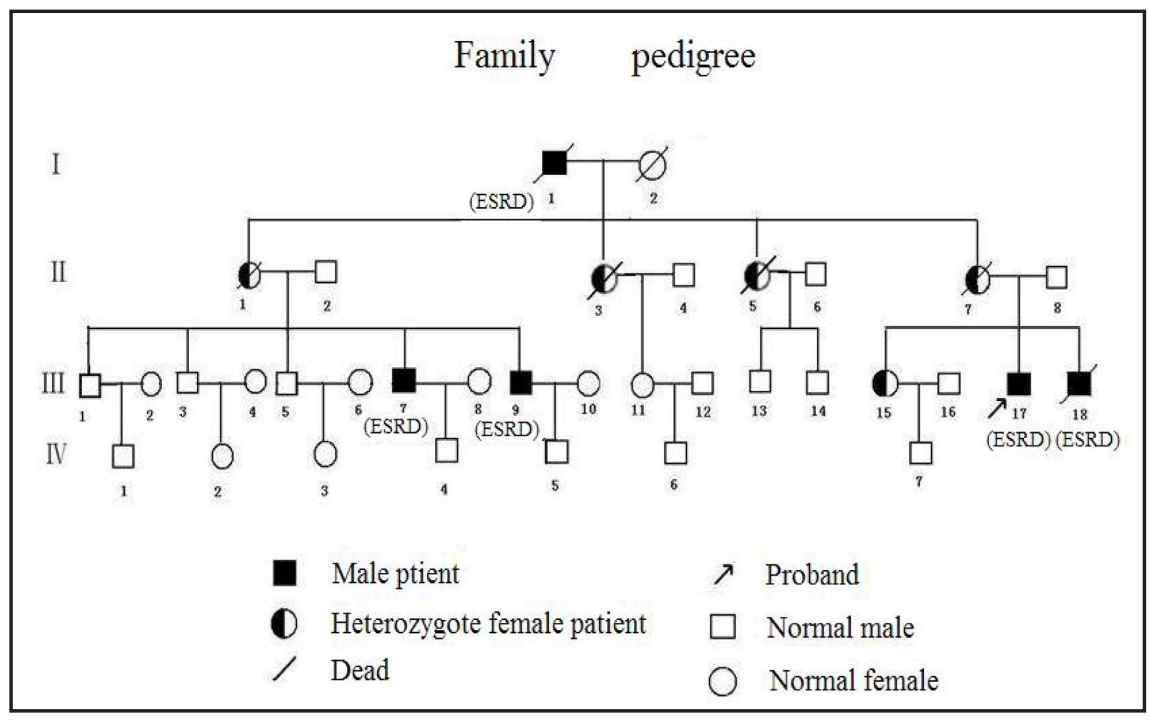

\section{Discussion}

In this study, we found a new FD family with renal failure in China. So far, over $600 \alpha$-gal A gene mutations causing FD have been described (Human Gene Mutation Database, http:// www.hgmd.cf.ac.uk). Different gene mutations might explain different clinical pictures but, at present time, genotype-phenotype correlations are premature because mutations are private [2]. The $\alpha$-gal A protein contains 429 amino acids that are important for enzymatic activity. To our knowledge, three mechanisms of enzymatic activity loss in FD have been proposed. First, gene mutations may induce incomplete proteins degradation by endosomes, leading to no enzymatic activity. Second, missense mutations in the critical active site or neighboring amino acids delete its enzymatic activity within lysosome, resulting in lack enzymatic activity during the production of $\alpha$-gal A proteins. Lastly, mutations may cause the destruction of protein transfer from the endoplasmic reticulum (ER) to the lysosomes, which accumulates $\alpha$-gal A in the ER and results in the absence of binding activity [10].

Our DNA sequencing of the proband demonstrated a single transition of $\mathrm{C}$ to $\mathrm{T}$ in codon 112 of exon 2 of $\alpha$-gal A gene. This missense mutation predicted an arginine to cysteine substitution (p.R112C). The R112C mutation, occurs at CpG dinucleotide, has been identified as the single causative lesion in several unrelated classically affected males [11-13]. The structural change due to replacement of arginine by cysteine results in an extremely unstable protein [14] . Cysteine is highly reactive and can be involved in the formation of disulfide bridges [15]. Nagy and Tanaka reported another two cases of FD with R112C mutation and only the cerebrum and the skin were affected [16-17]. They thought this mutation might affect an isoform of the enzyme which exerts its action mainly in the ectodermal tissues, leading to the limited organic manifestation. In the present study, the patient II7 manifested recurrent strokes and both the proband and his brother III18 had skin lesions, which was consistent with the previous reports on the organ damages induced by $\mathrm{R} 112 \mathrm{C}$ mutation. It has been known that $\mathrm{R} 112 \mathrm{C}$ mutation consequently relates to the damage of ectodermal tissues. However, the R112C mutation in this family resulted in the damage of both ectodermal and mesoderm tissues. Moreover, in this family, the more severe manifestation was the renal damage, and all of the five male patients developed ESRD. Thus, our report, for the first time, revealed that the $\mathrm{R} 112 \mathrm{C}$ mutation leading to FD in a Chinese pedigree was also correlated with renal damage symptoms. 


\section{Kidney \\ Blood Pressure Research}

Fig. 3. Sequence analysis of cDNA. A: A single C-to-T transition in codon 112 of exon 2 in the proband (patient III17) was detected by direct DNA sequencing. This was a missense mutation predicting an arginine to cysteine substitution (R112C). B: Basyls T and C were both found in patient III15, which indicated that the proband's sister was a heterozygote. C: Normal control.

Some researchers presented that the rate of renal development might be different due to gender or generation difference even within the same family with FD [18]. The presentstudy demonstrated that, in the family with FD, all five male patients who developed ESRD were from three different generations. Therefore, it seems that environmental or genetic (modifier genes) factors might also be involved [18]. By reviewing the disease history of the proband, we found some early signs and symptoms before the kidneys were badly damaged, including hypohidrosis, painful acroparesthesia, intolerance of heat and physical effort. These early typical onset of FD was due to the neural damage of small nerve fibers of the peripheral somatic nerve system [19]. Pain may wane in adulthood, so it is important to search for a medical history of acroparesthesia in childhood during the first examination of a newly diagnosed adult FD patient [20]. In fact, FD patients usually show three clinical phases: the first phase occurs in childhood and adolescence, characterized by acroparesthesia, myalgia, arthralgia, fever, cutaneous angiokeratomas, and corneal opacities. The second clinical phase is characterized by renal involvement (microalbuminuria and subsequent proteinuria, lipiduria with Malta cross crystals in the urine sediment, and impairment in the urine concentration and diluting capacity). In the third clinical phase severe renal damage is present with late involvement of cardiovascular and cerebrovascular systems [2]. In this family, there were 3 heterozygous females carriers. Two of which were asymptomatic and one manifested recurrent strokes. Clinical signs and symptoms vary widely in heterozygous females. This phenotypic heterogeneity is thought to be partly due to lyonization [21]. Moreover, it is well known that clinical manifestations of FD are protean; probably the residual $\alpha$-gal A activity modulates the phenotype in the patients, but this possibility has not been demonstrated. Such variability in symptom severity should be kept in mind when assessing and diagnosing potential patients.

Renal transplantation is considered an optimal option for FD patients with end-stage renal failure, despite their high risk for cardiovascular complications; in the past, kidney transplantation has been considered by some authors as a possible way for correcting the $\alpha$-gal A deficiency through enzyme replacement by a normal organ producing $\alpha$-gal A. The recurrence of FD in a renal allograft has been reported rarely. 


\section{Kidney \\ Blood Pressure Research}

\begin{tabular}{l|l}
\hline Kidney Blood Press Res 2013;37:221-228 \\
\hline DOI: $10.1159 / 000350147$ & $\begin{array}{l}\text { C } 2013 \text { S. Karger AG, Basel } \\
\text { www.karger.com/kbr }\end{array}$ \\
\hline Published onlIne: June 08, 2013 &
\end{tabular}

Wang/Wang/Zhu/Xiong: Gene Mutation of $\alpha$-gal A in a Chinese FD Family

Enzyme replacement therapy (ERT) with recombinant human $\alpha$-gal A was introduced since 2001. There are currently two commercially available enzyme preparations for FD: agalsidase alfa (Rep lagal $\AA$; S hire, Cambridge, MA, USA), produced using cultured human skin fibroblasts and registered for use at a dose of $0.2 \mathrm{mg} / \mathrm{kg}$ biweekly; agalsidase beta (Fabrazyme®; Genzyme Corp, Cambridge, MA, USA) produced by the expression of human $\alpha$-gal A cDNA in Chinese Hamster Ovary (CHO) cells and registered for a use at $1.0 \mathrm{mg} / \mathrm{kg}$ biweekly [22]. Up to date, long term safety and efficacy of replacement therapy have been investigated in a lot of countries and ERT has been validated as a disease-specific therapeutic agent for patients with FD. The data of ERT in China is still limited due to the high costs of the treatment, and the patients in this family gave up ERT for the same reason.

\section{Conclusion}

The present results strongly demonstrated that the missense mutation, p.R112C, in $\alpha$-gal A gene induced the activity deletion and FD development correlated with renal damage. In view of the genetic implications, clinicians should be alerted to this possibility, especially with a positive family history of relevant clinical features, and determine individual treatment strategies for each patient using ERT to prevent the development of the disease.

\section{Acknowledgement}

This work was supported by National Natural Science Foundation of China (30800532) and New Teachers' Fund for Doctor Stations, Ministry of Education (200804871122). The authors declare that there are no conflicts of interest.

\section{References}

1 Brady RO, Gal AE, Bradley RM, Martensson E, Warshaw AL, Laster L: Enzymatic defect in Fabry's disease. Ceramidetrihexosidase deficiency. N Engl J Med 1967;276:1163-1167.

2 Sessa A, Meroni M, Battini G, Righetti M, Mignani R: Chronic renal failure, dialysis, and renal transplantation in anderson-Fabry disease. Semin Nephrol 2004;24:532-536.

-3 Sessa A, Meroni M, Battini G, Righetti M, Maglio A, Tosoni A, Nebuloni M, Vago G, Giordano F: Renal involvement in anderson-Fabry disease. J Nephrol 2003;16:310-313.

-4 Branton MH, Schiffmann R, Sabnis SG, Murray GJ, Quirk JM, Altarescu G, Goldfarb L, Brady RO, Balow JE, Austin Iii HA, Kopp JB: Natural history of Fabry renal disease: Influence of alpha-galactosidase a activity and genetic mutations on clinical course. Medicine (Baltimore) 2002;81:122-138.

-5 Zhang SH, Liu ZH, Zeng CH, Li SJ, Chen HP, Su J, Li LS: Fabry disease: Renal biopsy-proven cases from china. J Nephrol 2007;20:716-726.

-6 Desnick RJ, Allen KY, Desnick SJ, Raman MK, Bernlohr RW, Krivit W: Fabry's disease: Enzymatic diagnosis of hemizygotes and heterozygotes. Alpha-galactosidase activities in plasma, serum, urine, and leukocytes. J Lab Clin Med 1973;81:157-171.

-7 Sheu SS, Chan LP, Liao SC, Hsiao KJ, Shu KH, Lu YS, Cheng CH, Lian JD: Fabry's disease: Clinical, pathologic and biochemical manifestations in two chinese males. Zhonghua Yi Xue Za Zhi (Taipei) 1994;54:368-372.

8 Grewal RP: Stroke in Fabry's disease. J Neurol 1994;241:153-156.

-9 Kornreich R, Desnick RJ, Bishop DF: Nucleotide sequence of the human alpha-galactosidase a gene. Nucleic Acids Res 1989;17:3301-3302.

10 Suzuki K, Miura N, Kitagawa W, Suzuki S, Komatsuda A, Nishikawa K, Watanabe D, Imai H: Progressive renal failure despite long-term biweekly enzyme replacement therapy in a patient with Fabry disease secondary to a new alpha-galactosidase mutation of leu311arg (1311r). Clin Exp Nephrol 2011;15:916-920. 


\section{Kidney \\ Blood Pressure Research}

Wang/Wang/Zhu/Xiong: Gene Mutation of $\alpha$-gal A in a Chinese FD Family

11 Ishida S, Ichimura K, Yamakage A, Matsuzaki S, Yamazaki S: Missense mutation in exon 2 of alphagalactosidase a in a patient with Fabry disease. Arch Dermatol Res 1997;289:303-305.

12 Germain DP, Shabbeer J, Cotigny S, Desnick RJ: Fabry disease: Twenty novel alpha-galactosidase a mutations and genotype-phenotype correlations in classical and variant phenotypes. Mol Med 2002;8:306312.

13 Shabbeer J, Yasuda M, Luca E, Desnick RJ: Fabry disease: 45 novel mutations in the alpha-galactosidase a gene causing the classical phenotype. Mol Genet Metab 2002;76:23-30.

$\checkmark 14$ Wilcox WR, Oliveira JP, Hopkin RJ, Ortiz A, Banikazemi M, Feldt-Rasmussen U, Sims K, Waldek S, Pastores GM, Lee P, Eng CM, Marodi L, Stanford KE, Breunig F, Wanner C, Warnock DG, Lemay RM, Germain DP: Females with fabry disease frequently have major organ involvement: Lessons from the Fabry registry. Mol Genet Metab 2008;93:112-128.

15 Blaydon D, Hill J, Winchester B: Fabry disease: 20 novel gla mutations in 35 families. Hum Mutat 2001;18:459.

16 Nagy ZF, Bencsik K, Rajda C, Morvay M, Husz S, Voros E, Rolfs A, Honti V, Dobozy A, Vecsei L: A rare manifestation of Fabry's disease. Swiss Med Wkly 2007;137:130.

17 Tanaka N, Utsumi K, Seta T, Usuda K, Komaba Y, Katsumata T, Katsura KI, Sakamoto S, Katayama Y: Recurrent strokes in a young adult patient with Fabry's disease. Eur J Neurol 2005;12:486-487.

18 Grünfeld JP, Lidove O, Joly D, Barbey F: Renal disease in Fabry patients. J Inherit Metab Dis 2001;24:S71-S74; discussion 65.

19 Dutsch M, Marthol H, Stemper B, Brys M, Haendl T, Hilz MJ: Small fiber dysfunction predominates in Fabry neuropathy. J Clin Neurophysiol 2002;19:575-586.

20 Naleschinski D, Arning K, Baron R: Fabry disease--pain doctors have to find the missing ones. Pain 2009;145:10-11.

21 Lyon MF: Gene action in the x-chromosome of the mouse (mus musculus l.). Nature 1961;190:372-373.

22 Germain DP: Fabry disease. Orphanet J Rare Dis 2010;5:30. 